Spherical activated carbons for the adsorption of a real multicomponent VOC mixture

M. Ouzzine, A.J. Romero-Anaya, M.A. Lillo-Ródenas ${ }^{\sharp}$, A. Linares-Solano

${ }^{a}$ Grupo de Materiales Carbonosos y Medioambiente, Dpto. Química Inorgánica-IUMA, Universidad de Alicante, Ap. 99, E-03080, Alicante, Spain.

${ }^{1}$ Corresponding author. Phone: +34 965903545; Fax: +34 965903454.

E-mail address: mlillo@ua.es 


\title{
Spherical activated carbons for the adsorption of a real multicomponent VOC mixture
}

\author{
M. Ouzzine, A.J. Romero-Anaya, M.A. Lillo-Ródenas ${ }^{\sharp}$, A. Linares-Solano \\ a Grupo de Materiales Carbonosos y Medioambiente, Dpto. Química Inorgánica-IUMA, \\ Universidad de Alicante, Ap. 99, E-03080, Alicante, Spain.
}

\begin{abstract}
The objective of this work is to study the adsorption of a multicomponent gaseous mixture (acetaldehyde, formaldehyde, 2-propenal, 1,3-butadiene and benzene) in which the components are present at different concentration on spherical activated carbons (SACs). Attention is paid to the influence of the carbons' properties on such adsorption, especially their porosities and distributions. For this purpose, a series of spherical activated carbons were prepared by physical activation with $\mathrm{CO}_{2}$ of a commercial spherical carbon. Their physico-chemical properties were characterized by $\mathrm{N}_{2}$ adsorption-desorption isotherms, temperature programmed desorption and scanning electron microscopy. Measurements of the adsorption behavior of the volatile organic compounds (VOC) mixture on SACs were performed in a flow-typed fixed bed system at room temperature under atmospheric pressure. Regarding porosity, our results show that for this particular mixture SACs with narrow micropore size distribution and moderate porous texture development (surface area in the range of $1000 \mathrm{~m}^{2} / \mathrm{g}$ or even lower) exhibit higher multicomponent adsorption capacities than others with much larger porosity development. This can be explained considering that the VOC present in larger concentration in the mixture, aldehydes, present low adsorption affinities and its adsorption is enhanced in adsorbents with narrow micropore size distribution.
\end{abstract}

${ }^{1}$ Corresponding author. Phone: +34 965903545; Fax: +34 965903454.

E-mail address: mlillo@ua.es 


\section{Introduction}

Volatile organic compounds (VOC) are gas pollutants emitted from different sources and processes $[1,2,3]$. Considering the inherently hazardous effects of VOC on the environment and human health, in recent years the control of these emissions has attracted much attention $[4,5,6]$. Numerous technologies have been investigated for the elimination of VOC, including adsorption [7,8], catalytic combustion [9], photocatalytic oxidation [10], biological methods [11], and others [12]. Among them, adsorption has always been a prominent choice because of its efficiency and relatively low cost, especially in procedures for recovering high-value adsorbates and for its applicability to low concentrations $[13,14]$.

Investigation on the removal of gaseous VOC by adsorption has focused on single components, mostly from the groups of ketones, aromatics and alkanes $[15,16,17,18]$. From a characterization point of view, separate adsorption of each component in the same concentration range is the most suitable. However, in most real applications the organic compounds to be adsorbed are present in different concentration ranges, as it is the case in our study. The experimental measurement of the multicomponent adsorption equilibrium in real conditions is complex and not easy to analyze and, therefore, literature includes few experimental data for the adsorption of multicomponent mixtures of hydrocarbons $[19,20]$. Several factors need to be considered to describe the adsorption of mixtures. Among them, polarity [21], boiling point [22], molecular weight [21], molecular size [23] and VOC concentrations in the mixture are key factors for engineering process design and optimization of industrial gas recovery, especially when the number of components exceeds two [24,25,26]. One of the most important issues in adsorption technology is the choice of a proper adsorbent. To date, carbon materials provide high adsorption capacities for different compounds, due to their hydrophobicity, high specific surface area and pore size distribution [27,28]. Several authors have studied the adsorption of VOC using ACs with different conformations, such as powdered activated carbons (PACs) [29], granular activated carbons (GACs) [30], activated carbon fibers (ACFs) [31], carbon monoliths [32] or, recently, spherical activated carbons (SACs) $[16,17,33,34,35]$. 
SACs are receiving considerable attention for their various potential advantages over granular or powdered activated carbons, such as high wear resistance, high mechanical strength, good adsorption performance, high purity, low ash content, smooth surface, good fluidity, good packaging, low pressure drop, high bulk density, high micropore volume and controllable pore size distribution [36]. All these advantages have allowed SACs to be used in several applications, both in gas phase $[16,34,37,38]$ and in solution $[39,40]$.

The objective of this study is the adsorption of a real multicomponent gaseous mixture containing several compounds with different concentrations ranges (acetaldehyde (1400 ppmv), formaldehyde (114 ppmv), 2-propenal (94 ppmv), 1,3-butadiene (87 ppmv) and benzene (46 ppmv)) on spherical activated carbons (SACs). These adsorbents have been obtained from a commercial spherical carbon supplied by Gun-Ei Chemical Industry (SACUA1). SACUA2 to SACUA6 have been prepared by the so-called $\mathrm{CO}_{2}$ physical activation of SACUA1 at different activation times. In contrast, SACUA7 is a commercial SAC also provided by Gun-Ei. The adsorption of each organic in the mixture has been analysed, paying attention to which properties of the SACs are influencing their performance for this application (i.e. porosity, surface chemistry,...) and, especially, to the influence of these parameters in the relative adsorption percentage of each compound in the different samples tested.

\section{Experimental}

\subsection{Reagents used}

The VOC mixture used contains acetaldehyde (1400 ppmv), formaldehyde (114 ppmv), 2-propenal (94 ppmv), 1,3-butadiene (87 ppmv) and benzene (46 ppmv) in air. This mixture was prepared using three cylinders of gases with different components provided by Carbagas AG. Table 1 summarizes the properties of the components and the concentrations employed in the experiments. 
Table 1. Properties of components present in the VOC mixture and their final concentrations in the mixture.

\begin{tabular}{lcccc}
\hline Component & $\begin{array}{c}\text { Molecular weight } \\
(\mathrm{g} / \mathrm{mol})\end{array}$ & $\begin{array}{c}\text { Boiling point } \\
\left({ }^{\circ} \mathrm{C}\right)\end{array}$ & $\begin{array}{c}\text { Dipolar moment } \\
(\text { Debye })\end{array}$ & $\begin{array}{c}\text { Concentration } \\
(\mathrm{ppmv})\end{array}$ \\
\hline Acetaldehyde & 44 & 20 & 2.7 & 1400 \\
Formaldehyde & 30 & -20 & 2.2 & 114 \\
2-Propenal & 56 & 53 & 3.0 & 94 \\
1,3-Butadiene & 54 & -4 & 0 & 87 \\
Benzene & 78 & 80 & 0 & 46 \\
\hline
\end{tabular}

\subsection{Materials}

A commercial spherical carbon prepared from a phenolic resin by the process described in the Japanese Patent Publication (Kokoku) $\mathrm{N}^{\circ}$ 62-11611 and supplied by Gun-Ei Chemical Industry (Headquarters: Takasaki-shi, Gunma, Japan) has been used as the starting material. This material, referred to as SACUA1, has been used to prepare spherical activated carbons by physical activation with $\mathrm{CO}_{2}$. Also, a commercial spherical activated carbon from Gun-Ei, referred to as SACUA7, has been selected and studied.

\subsection{Preparation of activated carbons}

Activated carbons were prepared by physical activation with $\mathrm{CO}_{2}$ using the experimental procedure described in previously published studies [16,17]. A horizontal quartz furnace tube $2 \mathrm{~m}$. long and $0.07 \mathrm{~m}$. diameter was used, and the precursor was placed in a crucible. A precursor weight of $2 \mathrm{~g}$., a flow of $80 \mathrm{ml} / \mathrm{min}$ of $\mathrm{CO}_{2}$, heating at $10{ }^{\circ} \mathrm{C} / \mathrm{min}$ from room temperature to $880^{\circ} \mathrm{C}$ and times of activation of $3,5,10,15$ and 20 hours were used for preparing SACUA2 to SACUA6 samples. The nomenclature of the different spherical activated carbons derived from SACUA1 includes SACUA followed by a number that indicates the sequence from low to high activation time.

\subsection{Morphologies and densities of the materials}

Morphology of all the SACs was studied using Scanning Electron Microscopy (SEM). Bed density of the activated carbons (also called bulk, tap, packing density or apparent density) can be defined as the weight of porous solid per volume in the packing system, that is the adsorbent bed. This volume includes the volume of pores, both opened and 
closed, and the space volume between the solid particles. This magnitude was measured using an experimental procedure similar to that described by the D2854-89 ASTM method [41]. In our case, the density measurement was performed with $0.5 \mathrm{~g}$. of sample using a $10 \mathrm{ml}$ measuring cylinder.

Helium density was measured in an Accupyc 1330 pycnometer from Micromeritcs. This magnitude corresponds to the ratio weight of sample/volume of sample measured by helium, with the latter corresponding to the total solid volume including closed porosity.

\subsection{Thermogravimetric experiments}

Thermogravimetric analysis was employed to analyze the ash content in the materials. The experiments were performed according with the experimental procedure described in [42]. For thermogravimetric analysis $10 \mathrm{mg}$. of spherical carbon were used (heating at $10{ }^{\circ} \mathrm{C} / \mathrm{min}$ from room temperature to $950{ }^{\circ} \mathrm{C}$ under an air flow rate of $100 \mathrm{ml} / \mathrm{min}$ in a SDT 2960 DSC-TGA equipment.

\subsection{Textural properties}

Textural characterization of the samples was carried out by adsorption of $\mathrm{N}_{2}$ and $\mathrm{CO}_{2}$ at $-196{ }^{\circ} \mathrm{C}$ and $0{ }^{\circ} \mathrm{C}$, respectively, using ASAP 2020 from Micromeritics and Autosorb-6B from Quantachrome equipment, respectively [43,44,45,46]. Before analysis, the samples were outgassed at $250{ }^{\circ} \mathrm{C}$ for $4 \mathrm{~h}$. The BET equation was applied to the nitrogen adsorption data to get the apparent BET surface area $\left(\mathrm{S}_{\mathrm{BET}}\right)[43,44,45]$. The Dubinin-Radushkevich equation was applied to the nitrogen adsorption data to determine the total micropore volume (pores with size $<2 \mathrm{~nm}$ ) and to the carbon dioxide adsorption isotherms to determine narrow micropore volumes (pores with size $<0.7 \mathrm{~nm}$ ) [47]. Pore size distributions were obtained applying the non-local density functional theory (NLDFT) to the $\mathrm{CO}_{2}$ adsorption data at $0{ }^{\circ} \mathrm{C}$ using the software provided by Quantachrome [48].

\subsection{Oxygen surface characterization}

The oxygen surface chemistry of all the samples was analyzed by means of temperature-programmed desorption (TPD) experiments carried out in a DSC-TGA equipment (TA, Simultaneous SDT 2960) coupled to a mass spectrometer (Balzers, 
OmniStar) [49]. In these experiments, $10 \mathrm{mg}$ of sample were heated up to $950{ }^{\circ} \mathrm{C}$ (heating rate $20{ }^{\circ} \mathrm{C} / \mathrm{min}$ ) under a helium flow rate of $100 \mathrm{ml} / \mathrm{min}$.

\subsection{Adsorption experiments}

Adsorption studies of the multicomponent gaseous system were performed at laboratory scale in a fixed-bed reactor system (0.006 $\mathrm{m}$ inner diameter) coupled to a mass spectrometer (Balzers, OmniStar). The multicomponent mixture studied was constituted by acetaldehyde (1400 ppmv), formaldehyde (114 ppmv), 2-propenal (94 ppmv), 1,3butadiene ( $87 \mathrm{ppmv})$ and benzene $(46 \mathrm{ppmv})$ in air. The gases with the required concentration were provided by Carbagaz AG. The adsorption temperature was $20^{\circ} \mathrm{C}$. Before adsorption, the samples were outgassed at $250{ }^{\circ} \mathrm{C}$ for $4 \mathrm{~h}$. The weight of adsorbent was around $0.25 \mathrm{~g}$ and a flow of $100 \mathrm{ml} / \mathrm{min}$ of the gaseous multicomponent mixture was used. Through the graphical representation of the outlet concentration of each gas versus time the breakthrough curves can be obtained. Gravimetric adsorption capacity (g./100 g. SAC) was obtained by numerical integration of the breakthrough curves. The breakthrough time was calculated as the time at which the outlet concentration $(\mathrm{C})$ reached $10 \%$ of the inlet concentration $\left(\mathrm{C}_{0}\right)$.

\section{Results and discussion}

\subsection{Morphological analysis}

Morphology of spherical activated carbons has been studied using scanning electron microscopy (SEM). The measurement and calculation of mean particle size of the spherical activated carbons was performed by Origin. SEM images and the distribution of particle sizes are shown in Figure 1. As expected, the activation leads to a decrease in the mean particle [17]. Table 2 compiles information on the particle size distributions of the activated carbons. 


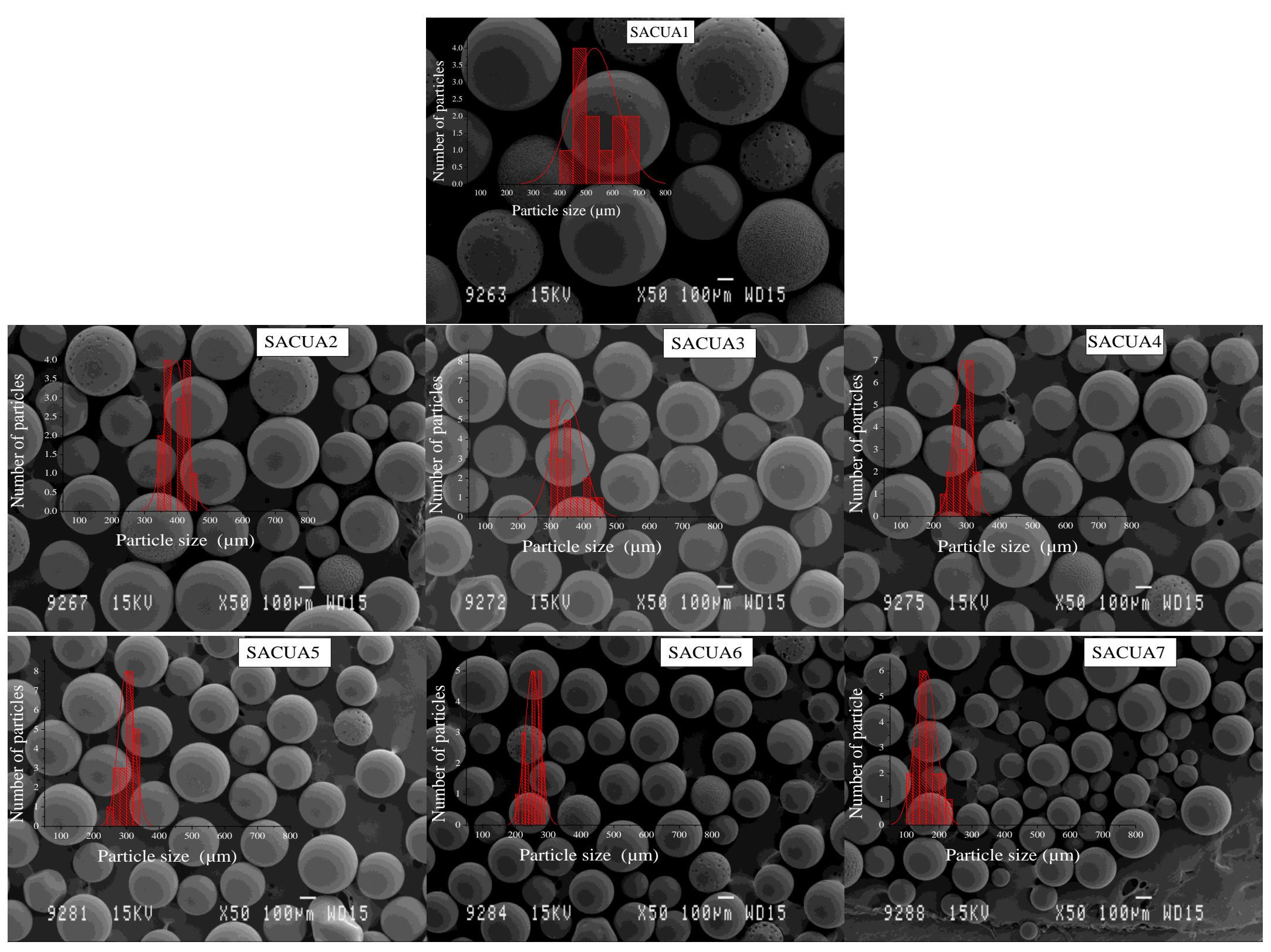

Fig. 1 - SEM images of the samples SACUA1 to SACUA7. 
Table 2. Particle size distributions for the activated carbons SACUA1 to SACUA7 (obtained by Origin).

\begin{tabular}{ccccc}
\hline Sample & $\begin{array}{c}\text { Minimum size } \\
(\mu \mathrm{m})\end{array}$ & $\begin{array}{c}\text { Maximum size } \\
(\mu \mathrm{m})\end{array}$ & $\begin{array}{c}\text { Mean size } \\
(\mu \mathrm{m})\end{array}$ & $\begin{array}{c}\text { Standard deviation } \\
(\mu \mathrm{m})\end{array}$ \\
\hline SACUA1 & 425 & 675 & 531 & 86 \\
SACUA2 & 350 & 450 & 395 & 32 \\
SACUA3 & 300 & 450 & 351 & 46 \\
SACUA4 & 240 & 338 & 299 & 24 \\
SACUA5 & 225 & 325 & 288 & 26 \\
SACUA6 & 200 & 285 & 252 & 23 \\
SACUA7 & 100 & 225 & 158 & 32 \\
\hline
\end{tabular}

From Figure 1 and Table 2 it can be concluded that after activation, the morphology of the activated carbons remains spherical, while mean particle size decreases with increasing activation times. According with Table 2, SACUA7 has the lowest mean particle size from the SACs, in the range of $160 \mu \mathrm{m}$.

\subsection{Thermogravimetric analysis}

The ash content of the materials was calculated from this analysis. All these SACs have very low ash content $(<0.05 \%)$, ruling out the possible complexities associated with catalytic reactions. This analysis (see Supplementary Material) also confirm that the SACs start to burn in air at quite high temperature (above $550{ }^{\circ} \mathrm{C}$ ), indicative of their thermal stability. This is an important issue if considering their application in industry. Also, as shown in the S.I., SACs decomposition occurs in one stage.

\subsection{Textural characterization}

Figure 2 shows the $\mathrm{N}_{2}$ adsorption isotherms and Table 3 compiles the activation times and textural properties of all the samples. $\mathrm{N}_{2}$ adsorption at low relative pressures in sample SACUA1 is negligible, which can be explained due to diffusional problems of nitrogen at this temperature in the narrow microporosity of this sample. From the nitrogen isotherms the microporous character of all the SACs can be clearly remarked. Isotherms are type $\mathrm{I}$, with the major $\mathrm{N}_{2}$ adsorption uptake occurring at relative pressures lower than 0.1 , being the adsorption almost constant at higher relative pressures. 


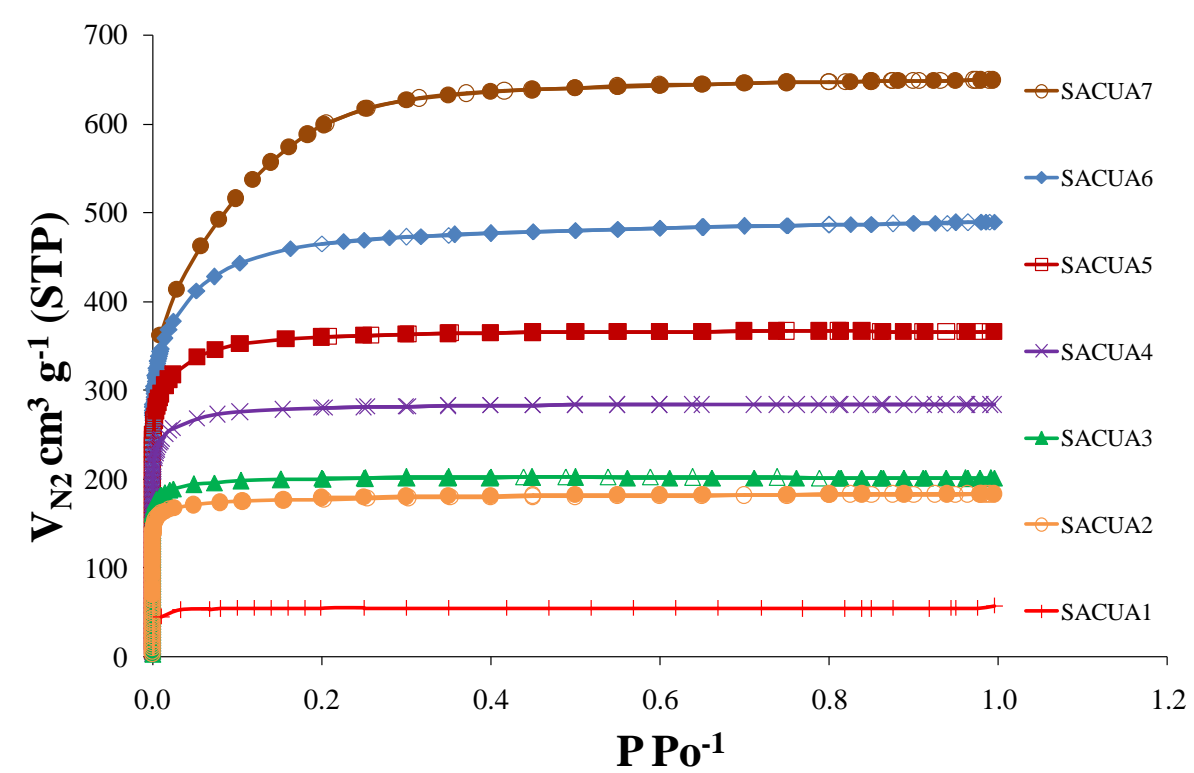

Fig. 2 - $\mathrm{N}_{2}$ adsorption-desorption isotherms at $-196^{\circ} \mathrm{C}$ of spherical activated carbons SACUA1-SACUA7 obtained in the ASAP 2020 from Micromeritics.

Table 3 also reveals some points: (1) the spherical carbon precursor used (SACUA1) can easily be activated with $\mathrm{CO}_{2}$, allowing the preparation of spherical activated carbons with a wide range of adsorption capacities (apparent BET surface areas and total micropore volumes) [16] as a function of the activation time; (2) both total and narrow micropore volumes develop with the activation time. However, (3), the larger the activation extent, the wider the micropore size distribution, as indicated by $\mathrm{V}_{\mathrm{DR}} \mathrm{CO}_{2}$ $-\mathrm{V}_{\mathrm{DR}} \mathrm{N}_{2}$. Note that a small difference between both micropore volumes indicates that most micropores of the sample are narrow with a mean pore size close to $0.7 \mathrm{~nm}$, whereas the larger the difference $\mathrm{V}_{\mathrm{DR}} \mathrm{CO}_{2}-\mathrm{V}_{\mathrm{DR}} \mathrm{N}_{2}$, the wider mean micropore size and distribution. 
Table 3. Textural properties and densities of the spherical activated carbons.

\begin{tabular}{l|c|ccc|c|c|cc}
\hline Sample & $\begin{array}{c}\text { Activation } \\
\text { time } \\
(\mathrm{h})\end{array}$ & $\begin{array}{c}\mathrm{S}_{\mathrm{BET}} \\
\left(\mathrm{m}^{2} \mathrm{~g}^{-1}\right)\end{array}$ & $\begin{array}{c}\mathrm{V}_{\mathrm{DR}} \mathrm{N}_{2} \\
\left(\mathrm{~cm}^{3} \mathrm{~g}^{-1}\right)\end{array}$ & $\begin{array}{c}\mathrm{V}_{\mathrm{DR}} \mathrm{CO}_{2} \\
\left(\mathrm{~cm}^{3} \mathrm{~g}^{-1}\right)\end{array}$ & $\begin{array}{c}\mathrm{V}_{\mathrm{DR}} \mathrm{CO}_{2}- \\
\mathrm{V}_{\mathrm{DR}_{2}} \\
\left(\mathrm{~cm}^{3} \mathrm{~g}^{-1}\right)\end{array}$ & $\begin{array}{c}\text { Mean } \\
\text { pore } \\
\text { size } \\
(\mathrm{nm}) *\end{array}$ & $\begin{array}{c}\text { Bed } \\
\text { density } \\
\left(\mathrm{g} \mathrm{cm}^{-3}\right)\end{array}$ & $\begin{array}{c}\text { Helium } \\
\text { density } \\
\left(\mathrm{g} \mathrm{cm}^{-3}\right)\end{array}$ \\
\hline SACUA1 & - & 200 & 0.004 & 0.21 & 0.206 & 0.52 & 0.85 & 2.04 \\
SACUA2 & 3 & 521 & 0.25 & 0.28 & 0.03 & 0.62 & 0.80 & 2.60 \\
SACUA3 & 5 & 671 & 0.33 & 0.32 & -0.01 & 0.62 & 0.76 & 2.77 \\
SACUA4 & 10 & 950 & 0.47 & 0.42 & -0.05 & 0.70 & 0.67 & 2.82 \\
SACUA5 & 15 & 1227 & 0.60 & 0.50 & 0.10 & 0.84 & 0.62 & 2.98 \\
SACUA6 & 20 & 1597 & 0.76 & 0.55 & -0.21 & 0.94 & 0.53 & 2.97 \\
SACUA7 & - & 2125 & 0.86 & 0.62 & -0.24 & 1.09 & 0.45 & 2.39
\end{tabular}

* Mean pore size for spherical activated carbons, obtained applying the non-local functional theory (NLDFT) to $\mathrm{CO}_{2}$ adsorption isotherms.

Figure 3 includes the pore size distributions obtained applying the non-local density functional theory (NLDFT) to the $\mathrm{CO}_{2}$ adsorption data at $0{ }^{\circ} \mathrm{C}$ for these ACs. This figure shows that porosity widens with the increase in the activation, both porosity distribution and mean pore size, included in Table 3 , in agreement with what was observed from $\mathrm{V}_{\mathrm{DR}} \mathrm{CO}_{2}-\mathrm{V}_{\mathrm{DR}} \mathrm{N}_{2}$ data. Thus, the sample with smallest mean pore size is SACUA1, the one used as precursor for preparing SACUA2 to SACUA6.

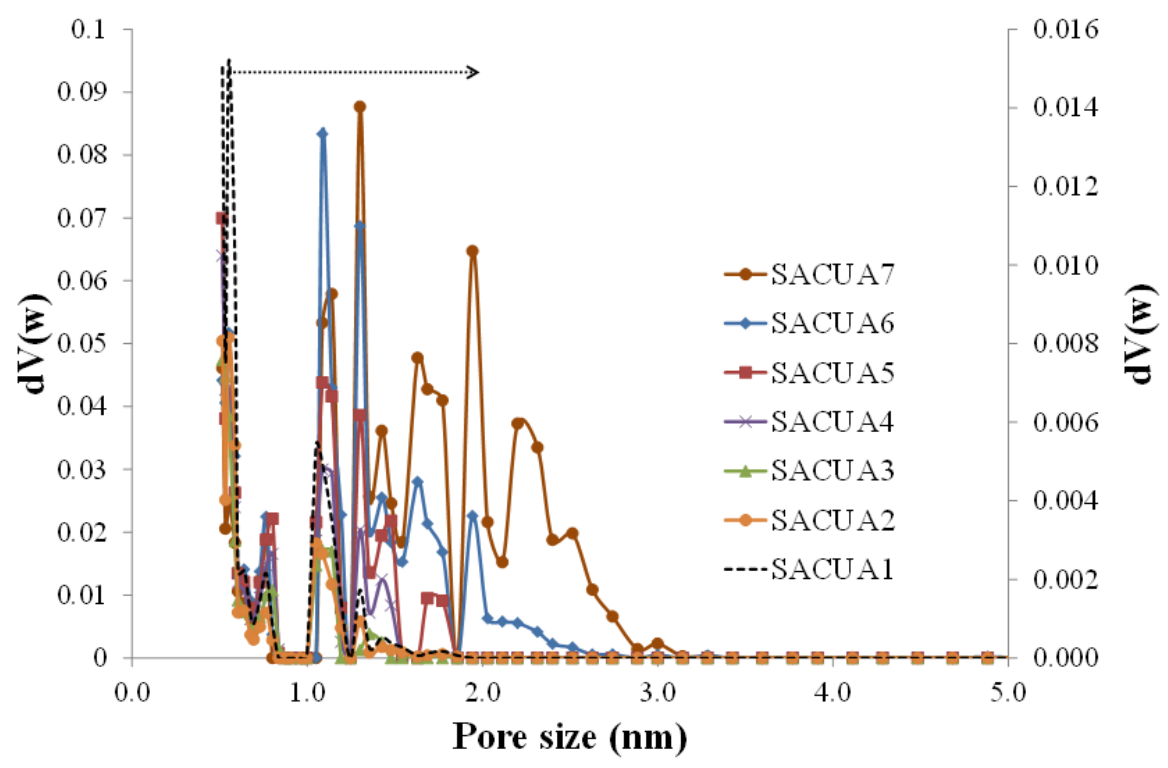

Fig. 3. Pore size distributions obtained applying the non-local density functional theory (NLDFT) to the $\mathrm{CO}_{2}$ adsorption data at $0{ }^{\circ} \mathrm{C}$ for spherical activated carbons SACUA1- 
SACUA7. Note that due to the low porosity of SACUA1 sample, its pore size distribution corresponds to a different scale (dashed line, secondary axis).

The results obtained from this figure complement the comments deduced above: (i) the microporosity of pristine SACUA1 develops upon activation and (ii) as expectable, with the increase in the degree of activation the micropore size distributions widen [16].

\subsection{Densities of materials}

Table 3 also presents the bed density of all SACs, defined as the mass of a unit of volume of the carbon material in air, including both porous system and the voids among the particles. This is an important variable for adsorption applications; it is important to obtain materials suitable textural properties together with high bed densities [17].

Changes in the bed density as a function of the degree of activation can be observed from Table 3 and Figure 4. As expected, bed density decreases with the increase in the degree of activation, and a well-defined relationship between both parameters can be found (see squares in Figure 4).

Regarding helium density, it increases with the degree of activation, from 2.04 to 2.97 $\mathrm{g} \cdot \mathrm{cm}^{-3}$, in contrast with the bed density, which decreases from 0.85 to $0.45 \mathrm{~g} \mathrm{~cm}^{-3}$. This is all in agreement with the fact that the resulting activated carbons have developed their porosity. It is important to remark that helium density of commercial SACUA7 is lower than those of spherical carbons prepared from SACUA1.

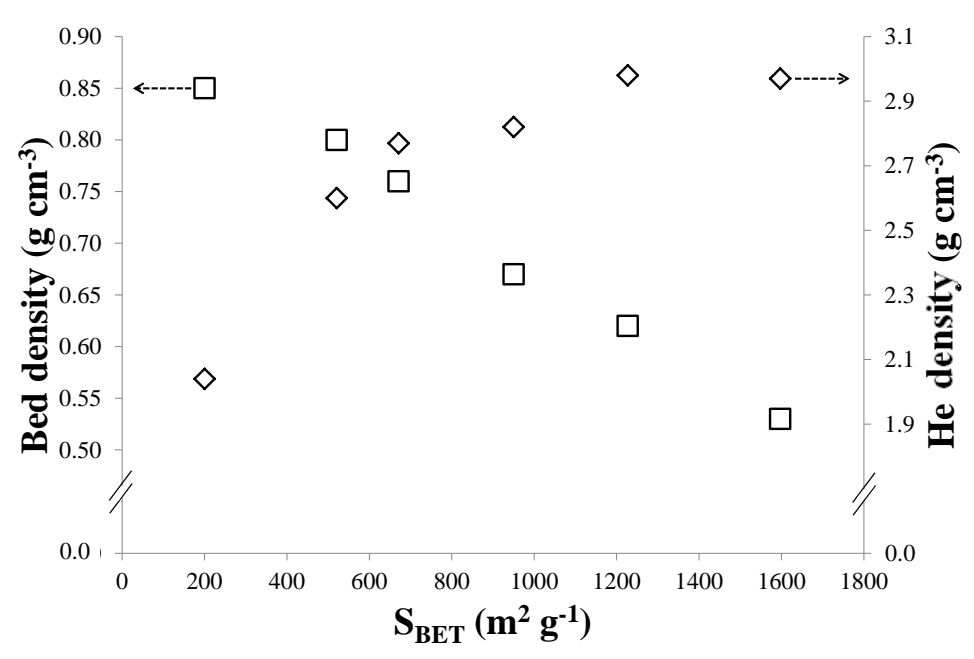

Fig. 4 - Relationship between surface areas and densities of SACs (bed density and Helium density). 


\subsection{Surface chemistry characterization}

The amounts of surface oxygen groups on these spherical activated carbons, which are released in the form of $\mathrm{CO}_{2}$ and $\mathrm{CO}$, have been determined by TPD, and are summarized in Table 4.

Table 4. Surface oxygen contents for the different spherical activated carbons.

\begin{tabular}{cccc}
\hline Sample & $\mathrm{CO}\left(\mu \mathrm{mol} \mathrm{g}^{-1}\right)$ & $\mathrm{CO}_{2}\left(\mu \mathrm{mol} \mathrm{g}^{-1}\right)$ & $\mathrm{O}_{\text {TOTAL }}\left(\mu \mathrm{mol} \mathrm{g}^{-1}\right)$ \\
\hline SACUA1 & 258 & 458 & 1174 \\
SACUA2 & 92 & 530 & 1153 \\
SACUA3 & 80 & 430 & 939 \\
SACUA4 & 76 & 513 & 1102 \\
SACUA5 & 256 & 522 & 1300 \\
SACUA6 & 172 & 293 & 759 \\
SACUA7 & 896 & 612 & 2119 \\
\hline \multicolumn{5}{c}{${ }^{*} \mathrm{O}_{\text {TOTAL }}=\mathrm{CO}+2 \mathrm{CO}_{2}$} \\
\hline
\end{tabular}

Some differences in the surface chemistry of these materials are observed. In general, the total oxygen contents are below $1300 \mu \mathrm{mol} \mathrm{g}{ }^{-1}$, being remarkable the high oxygen content in sample SACUA7 $\left(2119 \mu \mathrm{mol} \mathrm{g}{ }^{-1}\right)$ and the low content in SACUA6 (759 $\mu \mathrm{mol} \mathrm{g}^{-1}$ ). The low amount of surface oxygen groups for the spherical activated carbons prepared from SACUA1 (SACUA2 to SACUA6) in comparison with commercial SACUA7 makes these ACs interesting for their application for the adsorption of nonpolar organic compounds [34].

We have no information about SACUA7 preparation conditions, which can be very different to those used for preparation of SACUA2 to SACUA6. Its high oxygen content and the low content in SACUA6, despite their similar porosity development, suggests that SACUA7 was prepared by steam activation in contrast to our prepared samples, activated with $\mathrm{CO}_{2}$.

\subsection{Adsorption of gases from a multicomponent system}

A complex VOC gaseous mixture $(100 \mathrm{ml} / \mathrm{min}$ flow rate) containing five organic compounds from different nature and in different concentrations, from 46 to 1400 ppmv, was used in the adsorption tests. Inlet and outlet flow rates have measured and 
they are coincident, which highlights one of the advantages of the selection of spherical activated carbons for gaseous phase applications. An example of an adsorption breakthrough experiment is shown in Figure 5.

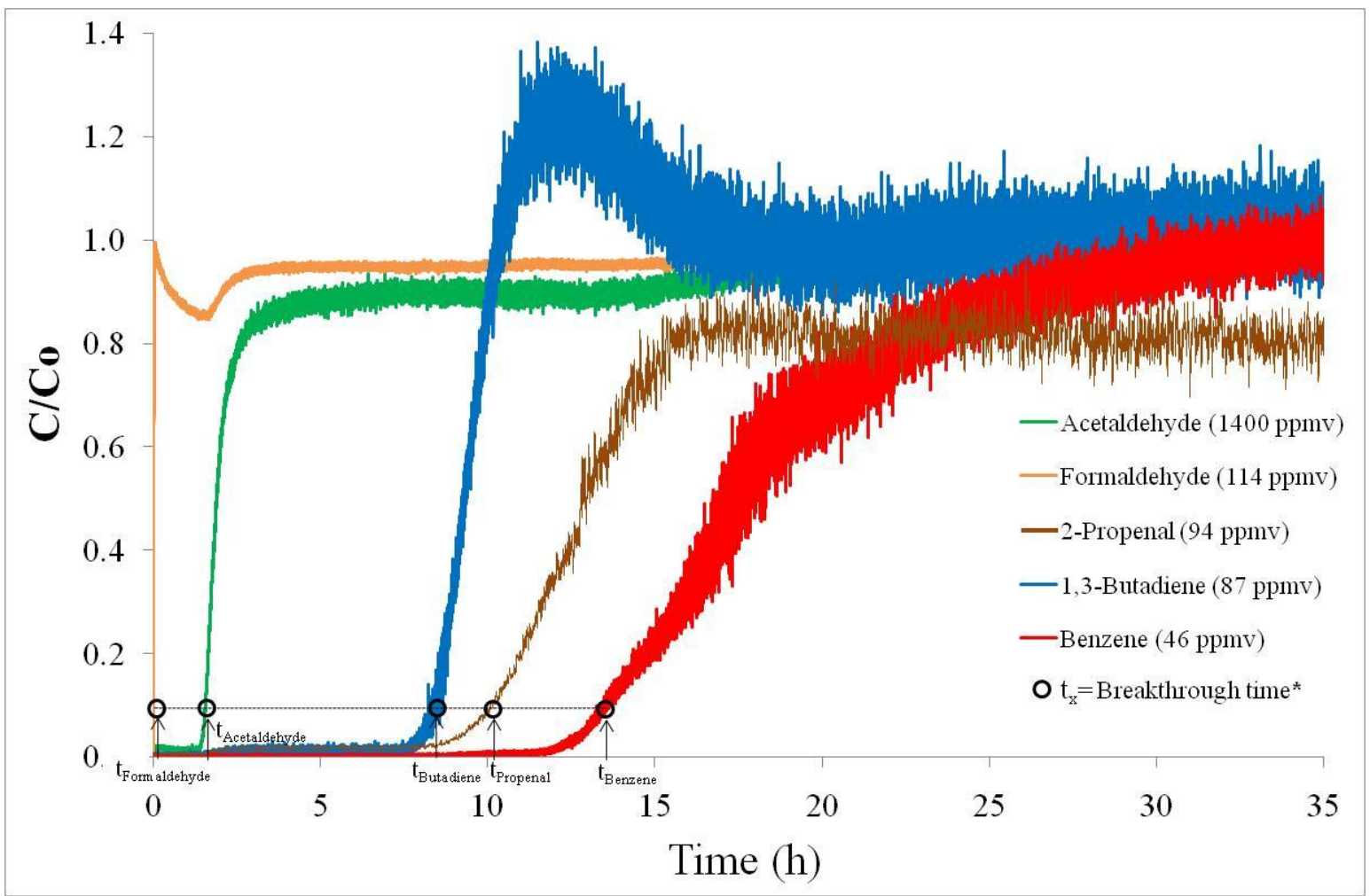

Fig. 5 - Breakthrough curves of gases adsorption plotted versus time for sample SACUA2. $\mathrm{t}_{\mathrm{x}}$ is breakthrough time at which the outlet concentration reaches the $10 \%$ of the inlet concentration.

As expected, Figure 5 shows differences in the adsorption of these organic compounds. A very low amount of acetaldehyde and, especially, formaldehyde are adsorbed, whereas 1,3-butadiene, 2-propenal and benzene are adsorbed up to a larger extent.

In principle, the low formaldehyde adsorption was a surprising result. This compound was the least adsorbed one from those in the adsorption mixture, and this result was observed for all the SACs and in repeated (reproducibility) tests. Previous data from the adsorption of single formaldehyde gas from the literature have shown an appreciable adsorbed amount of this compound, which is influenced by the adsorbent textural properties but, especially by its surface chemistry [50]. However, the results obtained in the present study highlight that formaldehyde and acetaldehyde are absorbed up to a low extent. To explain these facts, especially, the low formaldehyde adsorption, it should be 
recalled that the adsorption capacity of an activated carbon for an adsorbate depends, among others, on the adsorbate molecular weight and boiling point [51] and, according to Table 1 formaldehyde presents the lowest values of these parameters from all the studied adsorbates. This, together with the facts that: 1) formaldehyde is present at 10 times lower concentration than acetaldehyde and 2) the spherical activated carbons prepared show low surface chemistry contents explains the low formaldehyde adsorption capacities.

Figure 5 shows that 2-propenal, another aldehyde present in similar concentration as formaldehyde, is adsorbed up to a larger extent, which can be explained according to its physicochemical properties [51], such as its high boiling point (see Table 1).

Figure 5 confirms that breakthrough times for 2-propenal $(10.1 \mathrm{~h}), 1,3$-butadiene $(8.3 \mathrm{~h})$ and benzene $(13.5 \mathrm{~h})$ are larger than for acetaldehyde. However, it should be highlighted that their adsorption capacities depend, as well, on their concentrations.

Figure 5 also shows for 1,3-butadiene a common phenomenon occurring in multicomponent adsorption processes, so called roll-up. This phenomenon occurs when the concentrations of one/several component/s at the outlet of the fix bed exceed their inlet levels [52]. Some 1,3-butadiene desorption occurs due to the displacement by other compounds that are more strongly adsorbed, such as 2-propenal and benzene.

Figure 6 compiles the gravimetric adsorption capacity of each compound, in grams of the organic compound per $100 \mathrm{~g}$. AC, calculated by numerical integration of the breakthrough curves obtained for each AC. 


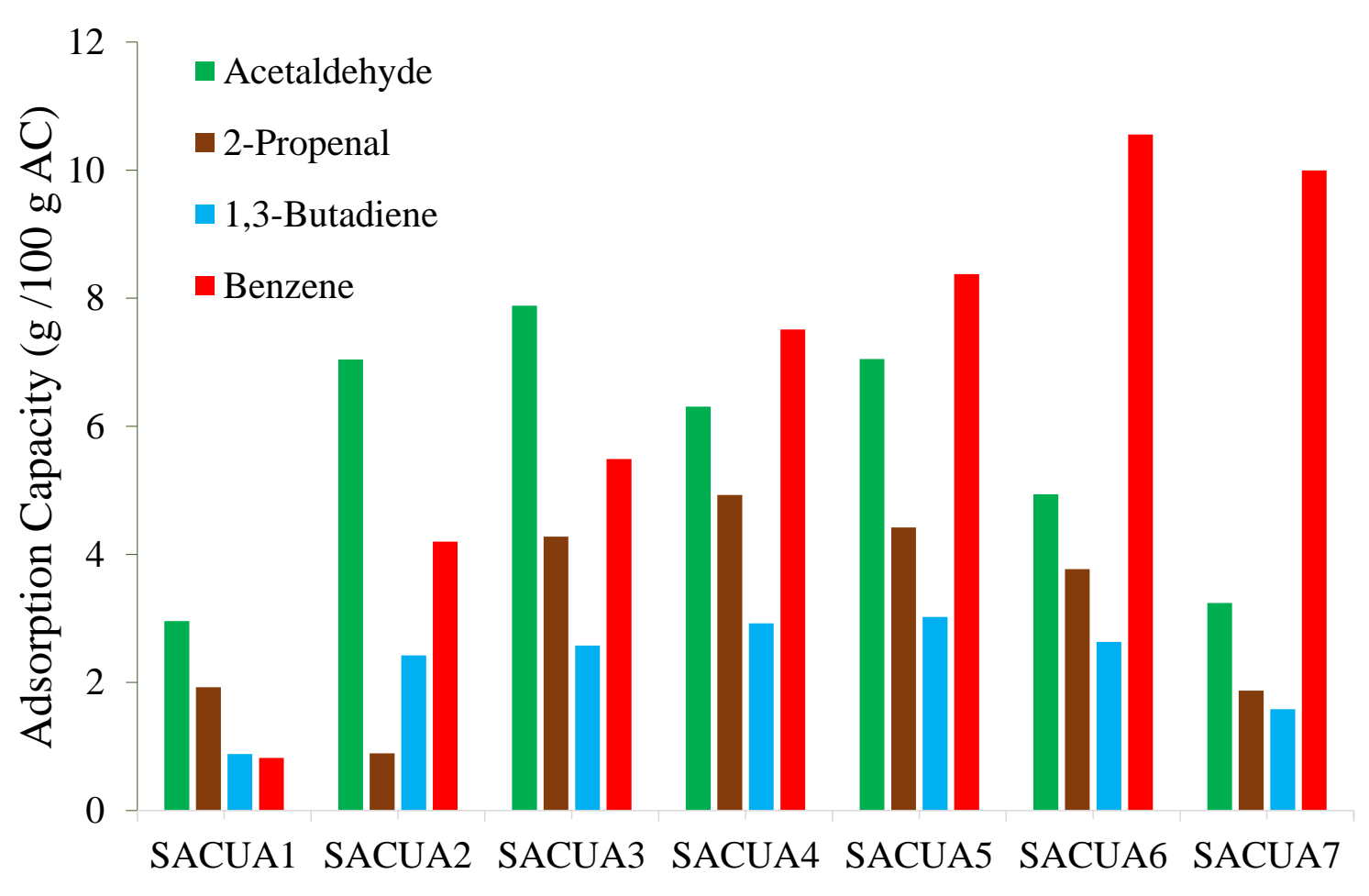

Fig. 6 - Gravimetric adsorption capacities for the SACs.

This figure shows that the four organic compounds are adsorbed up to a considerable extent in the ACs, being gravimetric adsorption capacities very different depending on the AC. In general, the adsorption capacity increases for more developed porosity in the materials, up to maximum value. Then, the adsorption capacity decreases with the activation degree. In relative terms, and without taking into consideration differences in their concentrations, acetaldehyde is "preferentially" adsorbed in SACs with lowmoderate porosity in comparison to other compounds, whereas benzene is mostly adsorbed for SACs with more developed porosity. This conclusion underlines the influence of pore size distribution in the preferential adsorption of some compounds over others.

Considering the molecular weight of each organic compound, molar adsorption capacities were also obtained, and are compiled in Table 5. 
Table 5. Molar adsorption capacity of each organic compound on the different SACs.

\begin{tabular}{cccccc}
\hline Sample & $\begin{array}{c}\text { Acetaldehyde } \\
\mathrm{mmol} / 100 \mathrm{~g} \\
\mathrm{AC}\end{array}$ & $\begin{array}{c}\text { 2-Propenal } \\
\mathrm{mmol} / 100 \mathrm{~g} \mathrm{AC}\end{array}$ & $\begin{array}{c}1,3-\text { Butadiene } \\
\mathrm{mmol} / 100 \mathrm{~g} \\
\mathrm{AC}\end{array}$ & $\begin{array}{c}\text { Benzene } \\
\mathrm{mmol} / 100 \mathrm{~g} \mathrm{AC}\end{array}$ & $\begin{array}{c}\text { Total amount } \\
\text { of VOC } \\
\mathrm{mmol} / 100 \mathrm{~g} \text { AC }\end{array}$ \\
\hline SACUA1 & 67 & 34 & 16 & 11 & 128 \\
SACUA2 & 160 & 16 & 45 & 54 & 275 \\
SACUA3 & 179 & 76 & 48 & 70 & 373 \\
SACUA4 & 143 & 88 & 54 & 96 & 381 \\
SACUA5 & 160 & 79 & 56 & 107 & 402 \\
SACUA6 & 112 & 67 & 49 & 135 & 363 \\
SACUA7 & 74 & 33 & 29 & 128 & 264 \\
\hline
\end{tabular}

From results of Table 5, several conclusions can be extracted:

- The molar adsorption capacities are very different depending on the AC.

The relative order of molar adsorption capacity, that is the compounds that adsorbed up to higher or lower extent, is also different depending on the AC, although some similarities are found. Thus, for most samples the highest molar adsorption capacity is that for acetaldehyde, except for SACUA6 and SACUA7. For these two samples, benzene is the most abundantly adsorbed compound in molar terms, although it is the one present in the mixture in the lowest concentration. These results highlight even more the fact the properties of the AC influence the preferential adsorption (and/or the adsorption displacement) of some organic compounds over others, despite the differences in the concentration of these compounds. This can be clearly concluded from the Scheme 1, which organizes, for each AC, the compounds from higher to lower molar adsorption capacities: 


\begin{tabular}{|c|c|c|c|c|}
\hline & \multicolumn{2}{|c|}{} & \multicolumn{2}{c|}{} \\
\cline { 5 - 5 } & \multicolumn{2}{|c|}{ Largest molar adsorption capacity } & \multicolumn{2}{c|}{ Lowest molar adsorption capacity } \\
\hline SACUA1 & Acetaldehyde & 2-Propenal & Butadiene & Benzene \\
\hline SACUA2 & Acetaldehyde & Benzene & Butadiene & 2-Propenal \\
\hline SACUA3 & Acetaldehyde & 2-Propenal & Benzene & Butadiene \\
\hline SACUA4 & Acetaldehyde & Benzene & 2-Propenal & Butadiene \\
\hline SACUA5 & Acetaldehyde & Benzene & 2-Propenal & Butadiene \\
\hline SACUA6 & Benzene & Acetaldehyde & 2-Propenal & Butadiene \\
\hline SACUA7 & Benzene & Acetaldehyde & 2-Propenal & Butadiene \\
\hline
\end{tabular}

Scheme 1. Classification of the higher to the lower molar adsorption capacity-adsorbed compounds in the different ACs.

- Keeping in mind the similarities in surface chemistry of SACUA1 to SACUA5, with total surface oxygen contents in the range of $1100 \mathrm{micromol} / \mathrm{g}$, and considering the total surface oxygen contents for SACUA6 and SACUA7, 759 and $2119 \mathrm{micromol} / \mathrm{g}$, respectively, the different preferential adsorption of some compounds respect to others is not provoked by differences in surface chemistry. Note the different adsorbed compounds relative order in SACUA2, SACUA3 and SACUA4, as an example. Differences in porous texture (in mean pore sizes, pore volumes and/or porosity distributions) are strongly influencing the obtained results, what remarks the need of a suitable characterization of these ACs properties.

- The total molar adsorption capacity of the five compounds has been calculated for the different adsorbents, showing this order: SACUA5 > SACUA4 > SACUA3 > SACUA6 > SACUA2 > SACUA7 > SACUA1. Surprisingly, if the goal is to adsorb the highest (molar) amount of VOC, optimum adsorbents are not those showing the largest porosity development, but some with moderate porosity development and, probably, more appropriate porosity distributions.

One important issue that has to be considered is the fact that the organic compounds are present in the mixture in very different concentrations (i.e. $1400 \mathrm{ppmv}$ for acetaldehyde and $46 \mathrm{ppmv}$ for benzene). With the purpose of considering this, the 
molar adsorption capacities have been referred to the concentrations of each organic compound; that is these adsorption capacities have been normalized to their concentration in the gaseous mixture. This leads to some information respect to the percentage of the adsorbed organic compound respect to its initial concentration. Figure 7 shows this normalized adsorption efficiency for each organic compound in the corresponding SAC.

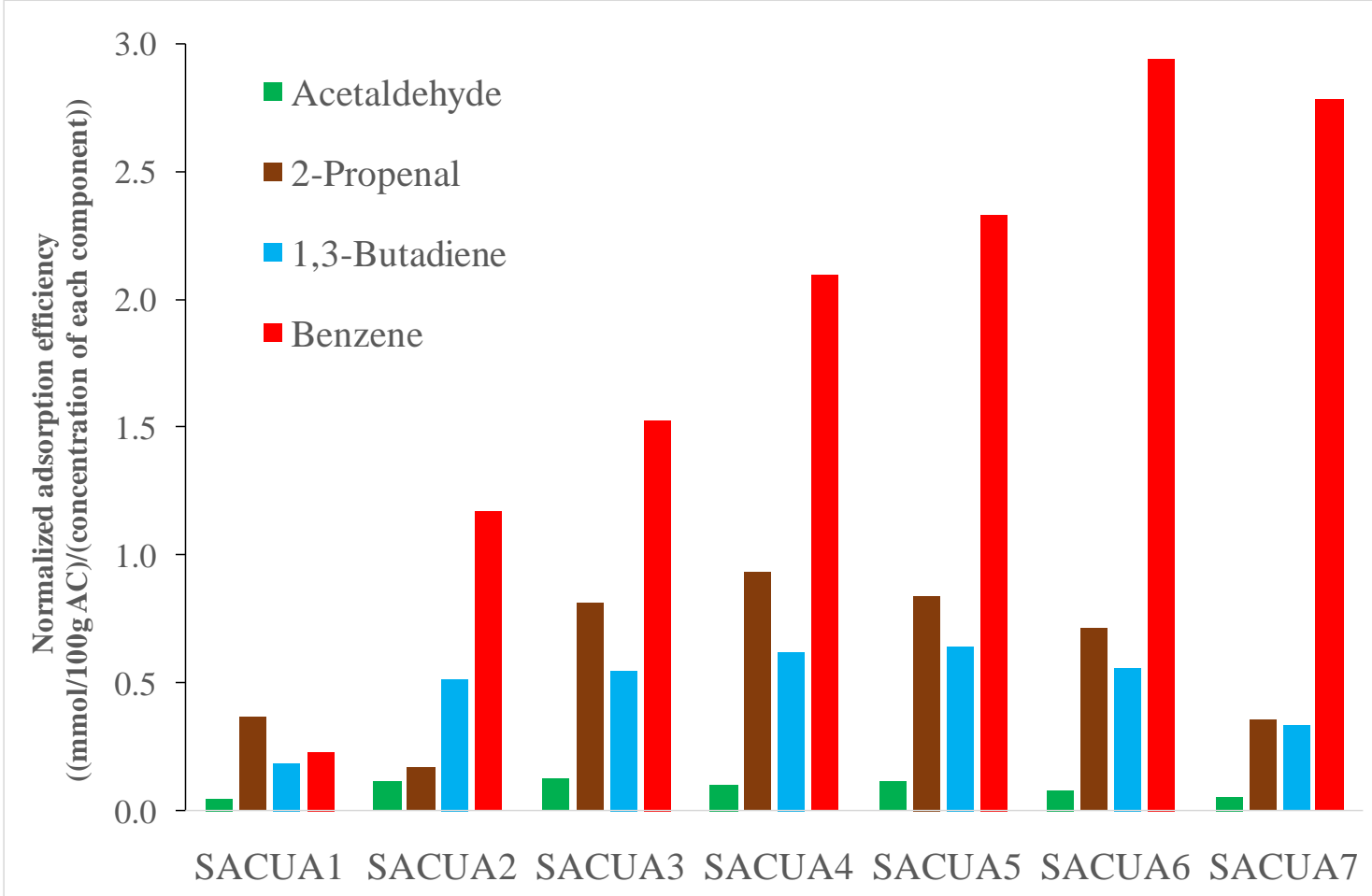

Fig. 7 - Normalized adsorption efficiency of each organic compound in the corresponding AC.

Figure 7 let us conclude that, in general, benzene (46 ppmv) is the most efficiently adsorbed organic compound, followed by 2-propenal (94 ppmv) and 1,3-butadiene (87 ppmv), whereas the adsorption of acetaldehyde, present in larger concentration (1400 ppmv), is less favored. Therefore, from this data the general relative order of the adsorption efficiencies can be concluded/established:

Benzene > 2-Propenal > 1,3-Butadiene > Acetaldehyde.

This relative order agrees very well with the molecular weight of these VOC and with their boiling points (see Table 2). Note that these trends are more easily comparable for 
2-propenal, benzene and 1,3-butadiene, whose concentrations in the gas phase are in the same order of magnitude.

The adsorption capacity for each organic compound has been calculated in Table 6 assuming that they are adsorbed as liquids in the micropores of SACs (using the liquid density of each organic compound), as it has been done in previous publications $[16,17]$. Additionally, and considering the volumes of both total micropores $\left(\mathrm{V}_{\mathrm{DR}} \mathrm{N}_{2}\right)$ and narrow micropores $\left(\mathrm{V}_{\mathrm{DR}} \mathrm{CO}_{2}\right)$ for each $\mathrm{SAC}$, the ratio of such micropore volumes (total or narrow ones) occupied by the organic compounds adsorbed as liquids are also presented in Table 6.

SACUA4 shows the largest total amount of VOC adsorbed in liquid form, 0.1087 $\mathrm{cm}^{3} / \mathrm{g}$, followed by SACUA5, whereas the largest percentage of both total and narrow micropore volumes occupied by the adsorbed VOC takes place in SACUA3 followed by SACUA4. These results remark again that although often in the literature the purpose is to obtain as highly activated carbons as possible, it is important to consider that depending on the goal, moderate porosity developments are preferred. This is explained considering that they lead to good bed densities and narrow micropore size distributions, much more interesting for applications/conditions such as the one/s being explored. 
Table 6. Adsorption capacity for each organic compound on the different SACs expressed as liquids, total adsorption capacities in liquid form and ratios between total adsorption capacities in liquid form and total or narrow micropore volume, respectively.

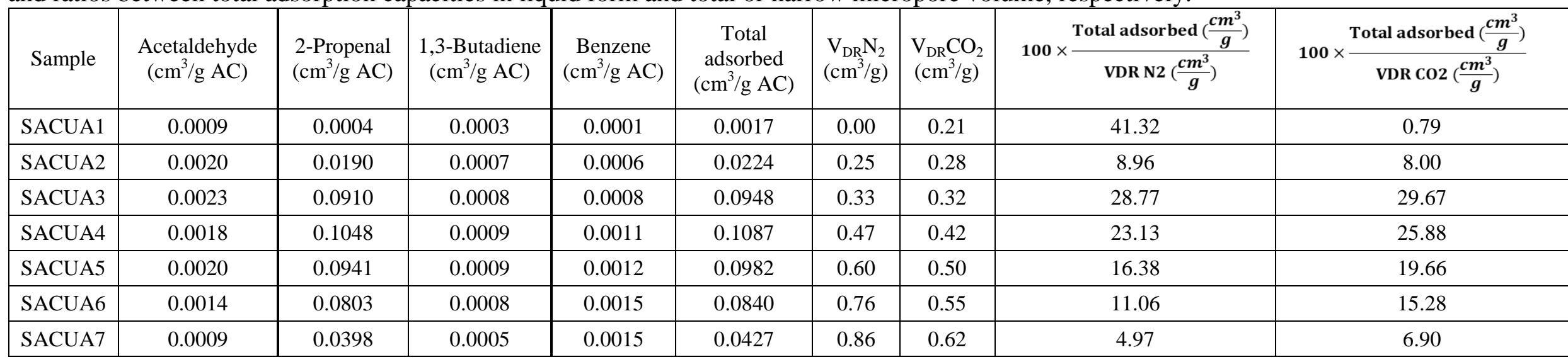




\subsubsection{Effect of porosity in the adsorption of the VOC mixture}

To analyze the effect of the textural properties, the molar adsorption capacity for each component has been plotted versus the BET surface area, total micropore volume and narrow micropore volume (Figure 8).

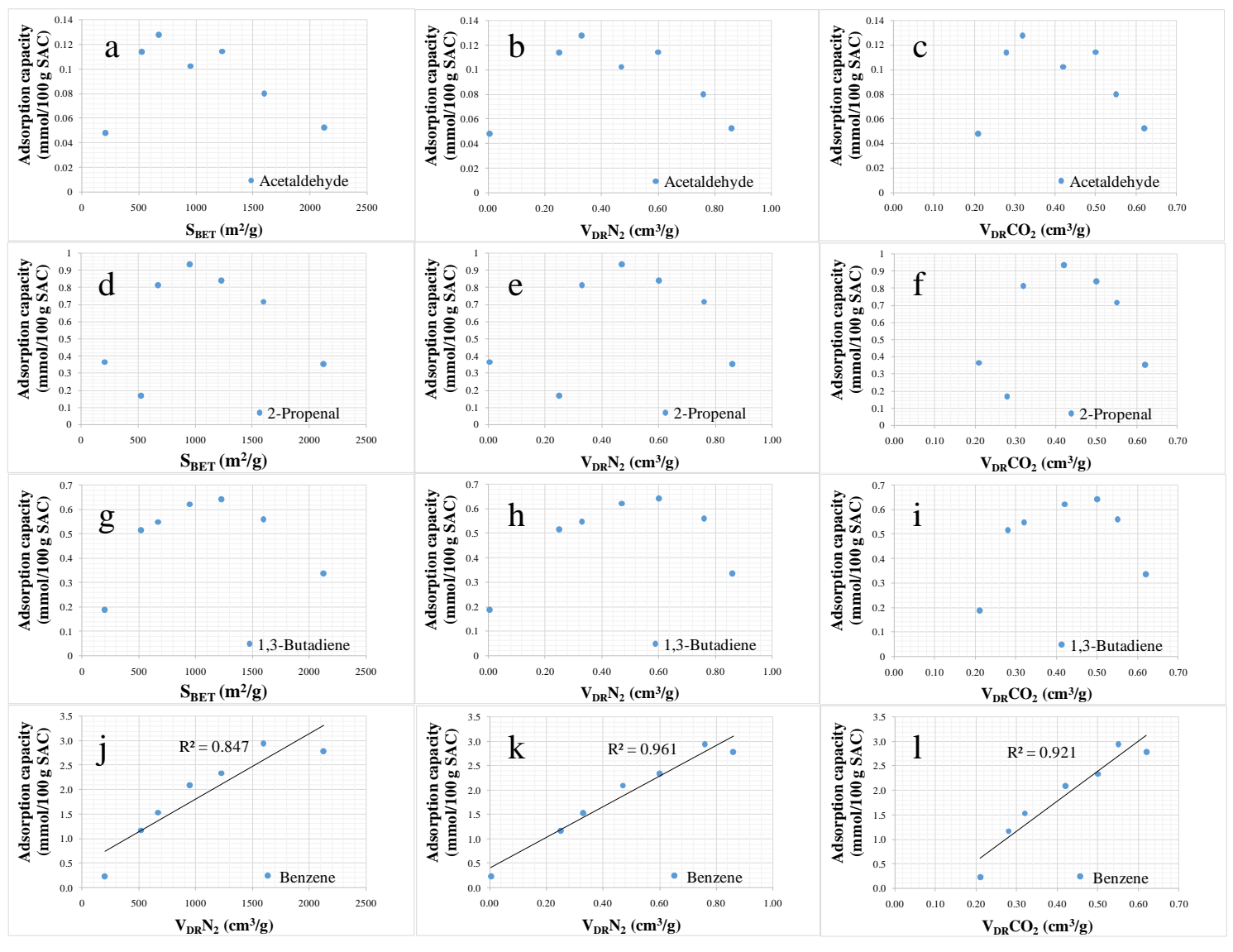

Fig. 8 - Relationship between textural properties of materials, $\mathrm{S}_{\mathrm{BET}}, \mathrm{V}_{\mathrm{DR}} \mathrm{N}_{2}$ and $\mathrm{V}_{\mathrm{DR}} \mathrm{CO}_{2}$, and molar adsorption capacity of each compound. (a, b, c) Acetaldehyde, (d,e,f) 2-Propenal, (g,h,i) 1,3-Butadiene, (j,k,1) Benzene.

Firstly, Figure 8 shows that, in agreement with what was commented above, acetaldehyde appears to have two maximum peaks for samples SACUA3 and SACUA5. This result indicates that SACs with moderate textural properties could enhance the adsorption capacity for this component.

Secondly, an adsorption maximum for 2-propene exists for SACUA4, whereas maximum 1,3-butadiene adsorption takes place in SACUA5, emphasizing that SACs 
with moderate textural properties are the most suitable for the adsorption of these components.

Thirdly, from Figure 8 it can also be seen that benzene adsorption capacity increases when the textural properties of the SACs materials (i.e. $\mathrm{S}_{\mathrm{BET}}, \mathrm{V}_{\mathrm{DR}} \mathrm{N}_{2}$ and $\mathrm{V}_{\mathrm{DR}} \mathrm{CO}_{2}$ ) improve. It can also be concluded that benzene adsorption capacity is linearly correlated with such textural properties of materials, especially; it has a better correlation with the total microporosity $\left(\mathrm{V}_{\mathrm{DR}} \mathrm{N}_{2}\right)$.

It could be said that higher benzene adsorption capacity (benzene concentration of 46 ppmv) could be related with its non-polar nature. The SACs prepared have low surface oxygen groups content (see Table 4), being these materials adequate for the adsorption of this gas in these conditions (low concentration), due to affinity between the properties of adsorbate and the surface of the material.

The obtained benzene adsorption results agree with those from previous publications $[53,54]$, showing that porosity and pore size distribution have an important microporosity and low surface chemistry [53,54]. According to these papers, the micropore volume seems to be one of the most important parameters affecting benzene adsorption at low concentration; a linear relationship between the VOC adsorption capacity and the micropore volume exists, especially for benzene [53,54]. Respect to the importance of surface oxygen groups, when reducing the content in these groups the activated carbons have higher benzene adsorption capacity [53].

However, not such clear relationship between their adsorption capacities with the SACs textural properties exist if focusing on other compounds. For this reason, and highlighting that some of the obtained results have shown that SACs with moderate porosity have shown maximum adsorption capacity values for acetaldehyde, 2-propenal and 1,3-butadiene, other factors should be considered. 
3.6.2. Discussion of the adsorption of the VOC mixture normalized to the surface area of the adsorbents.

To eliminate the influence of the BET surface area, and try to better understand the obtained results, the adsorption capacities of VOC in mixture have been normalized to BET surface area of the SAC, namely the normalized molar adsorption capacity per unit surface area (Q). The Q values for the different SACs are reported in Table 7.

Table 7. Some features of the porous texture characterization and normalized molar adsorption capacities per unit of surface area for the organic compounds in the different SACs.

\begin{tabular}{|c|c|c|c|c|c|c|c|}
\hline \multirow{2}{*}{ Sample } & \multirow{2}{*}{$\begin{array}{c}\mathrm{S}_{\mathrm{BET}} \\
\left(\mathrm{m}^{2} / \mathrm{g}\right)\end{array}$} & \multirow{2}{*}{$\begin{array}{l}\text { Mean } \\
\text { pore } \\
\text { size } \\
(\mathrm{nm})\end{array}$} & \multicolumn{4}{|c|}{$\underset{\left(\mu \mathrm{mol} / \mathrm{m}^{2}\right)}{\mathrm{Q}}$} & \multirow[b]{2}{*}{ Total } \\
\hline & & & Acetaldehyde & $\begin{array}{c}2- \\
\text { Propenal } \\
\end{array}$ & $\begin{array}{c}1,3- \\
\text { Butadiene }\end{array}$ & Benzene & \\
\hline SACUA1 & 200 & - & 335 & 170 & 80 & 55 & 640 \\
\hline SACUA2 & 521 & 0.62 & 307 & 31 & 86 & 104 & 528 \\
\hline SACUA3 & 671 & 0.62 & 267 & 113 & 72 & 104 & 556 \\
\hline SACUA4 & 950 & 0.70 & 151 & 93 & 57 & 101 & 402 \\
\hline SACUA5 & 1227 & 0.84 & 130 & 64 & 46 & 87 & 327 \\
\hline SACUA6 & 1597 & 0.94 & 70 & 42 & 31 & 85 & 228 \\
\hline SACUA7 & 2125 & 1.09 & 35 & 16 & 14 & 60 & 125 \\
\hline
\end{tabular}

Q: Molar adsorption capacity normalized to surface area $\left(\mu \mathrm{mol} / \mathrm{m}^{2}\right)$.

When normalizing the molar adsorption to surface area, the SACs with low-moderate surface area exhibit the best performances in global terms (if focusing on total molar adsorption capacity), governing acetaldehyde, 2-propenal and 1,3 butadiene this behaviour. Especially for acetaldehyde and 2-propenal, the larger the porosity development, the lower the molar adsorption per unit of surface area. In contrast for benzene, maximum Q values are obtained with SACs with intermediate porosities.

In principle, it might seem difficult to explain these results. Let us remind that the molar adsorption capacities are normalized to the surface area of the SACs. However, they can be well-understood if focusing on the different pore size distributions in the SACs, exemplified by the mean pore sizes compiled in Table 7 . When the compounds have large affinity to carbon, such as benzene, it is not so crucial to have adsorbents with very narrow porosity distributions, and their maximum adsorption capacities are achieved with carbons presenting intermediate pore size distributions. In contrast, for lower adsorption affinities (acetaldehyde, 2-propenal), the highest molar adsorption 
capacities are obtained with low porosity developments because of the smaller mean pore sizes, that lead to higher adsorption potential for such low sized micropores.

\section{Conclusions}

The present work deals with physical activation process $\left(\mathrm{CO}_{2}\right)$ of a commercial spherical activated carbon and the use of these materials for adsorption of multicomponent gaseous mixture with different concentrations. The SACs prepared maintain the spherical morphology after activation process. However, the mean particle size and bed density, as expected, decreased when the porosity was developed. The spherical activated carbons derived from SACUA1 have developed the microporosity, obtaining surface areas up to $1600 \mathrm{~m}^{2} / \mathrm{g}$ with the micropore volume and narrow micropore volume of $0.76 \mathrm{~cm}^{3} \mathrm{~g}^{-1}$ and $0.55 \mathrm{~cm}^{3} \mathrm{~g}^{-1}$, respectively.

The factors governing adsorption of the VOC mixture onto spherical activated carbons were discussed, and the following conclusions can be highlighted:

- The adsorption capacities obtained are very different, keeping in mind the different nature and concentration of each component. Benzene is the most efficiently adsorbed organic compound, as a result of its physical properties, such its higher molecular weight (boiling point) and its lower polarity (see Table 1), followed by 2-propenal and 1,3-butadiene, whereas the adsorption of acetaldehyde, present in larger concentration, is less favored. Formaldehyde adsorption from this mixture is negligible, being boiling point/molecular weight (see Table 1) two of the adsorbate properties that provide information about the affinity adsorbate-carbon and explain the acetaldehyde and formaldehyde adsorption results. It must be recalled that most SACs present low surface oxygen contents, which favor the adsorption of non-polar adsorbates.

- Linked to this, the different preferential adsorption of some compounds respect to the others is not provoked by differences in surface chemistry, since most activated carbons have similar surface oxygen groups' contents. Mean micropore sizes, micropore volumes and porosity distributions considerably affect the adsorption process. 
- The total molar adsorption capacity of the VOC mixture for the different adsorbents shows this order: SACUA5 $>$ SACUA4 $>$ SACUA3 > SACUA6 > SACUA2 > SACUA7 > SACUA1. Surprisingly, if the goal is to adsorb the highest amount of VOC, optimum adsorbents are not those showing the largest porosity development, but some with moderate porosity development and suitable porosity distributions.

- When normalizing the molar adsorption to surface area, the SACs with lowmoderate surface area exhibit the best performances in global terms, governing acetaldehyde, 2-propenal and 1,3 butadiene this behaviour. For benzene, in contrast, maximum $\mathrm{Q}$ values are obtained with SACs with intermediate to large porosity developments.

- Boiling point/molecular weight are important parameters, which have to be taken into account to study the adsorption of a gaseous VOC mixture. These properties influence the affinity of the organic compounds for being adsorbed on SACs, and they are linked to the most suitable pore size distributions to enhance their adsorption capacities.

All these results highlight that depending on the goal, it is important to consider that moderate porosity developments, which usually lead to good bed densities and narrow micropore size distributions, can be much more interesting than more developed porous textures. Thus, our results have shown that moderate porosity developments (in the range of $1000 \mathrm{~m}^{2} / \mathrm{g}$ ) are preferred if the desired target is to achieve as high molar adsorption capacities as possible (and the gas mixture has some similarities with the one studied). Hence, when organic compounds with low affinities are the main components in a gaseous mixture, such low-moderate porosity ACs (with narrow micropore size distribution) enhance the adsorption potential. In contrast, if organic compounds with large affinities would be the main components in a gaseous mixture to be adsorbed (i.e. benzene would be the main component and/or present in the largest concentration, ACs with more developed porosities and larger micropore size distributions would likely be preferred. 


\section{Supplementary Material.}

Supplementary material shows details about thermogravimetric analysis of the prepared SACs.

\section{Acknowledgements}

The authors would like to thank Philip Morris International (PMI) for financial support.

\section{References}

[1] Tefera DT, Hashisho Z, Philips JH, Anderson JE, Nichols M. Modelling competitive adsorption of mixtures of volatile organic compounds in a fixed-bed of beaded activated carbon. Environ. Sci. Technol 2014; 48:5108-5117.

[2] Hernández MA, Velasco JA, Asomoza M, Solis S, Rojas F, Lara VH, Portillo R, Salgado MA. Alkane adsorption on microporous $\mathrm{SiO}_{2}$ substrata. 1. Textural characterization and equilibrium. Energy Fuels 2003; 17:262-270.

[3] Gironi F, Piemonte V. VOCs removal from dilute vapour streams by adsorption onto activated carbon. Chem. Eng. J 2011; 172:671-677.

[4] Wang S, Ang HM, Tade MO. Volatile organic compounds in indoor environment and photocatalytic oxidation: State of the art. Environ. Int 2007; 33:694-705.

[5] Parmar GR, Rao NN. Emerging Control Technologies for Volatile Organic Compounds. Crit. Rev. Environ. Sci. Technol 2009; 39:41-78.

[6] He C, Xu LL, Yue L, Chen YT, Chen JS, Hao ZP. Supported Nanometric Pd Hierarchical Catalysts for Efficient Toluene Removal: Catalyst Characterization and Activity Elucidation. Ind. Eng. Chem. Res 2012; 51:7211-7222.

[7] Tefera DT, Jahandar LM, Fayaz M, Hashisho Z, Philips JH, Anderson JE, Nichols M. Two-dimensional modeling of volatile organic compounds adsorption onto beaded activated carbon. Environ. Sci. Technol 2013; 47:11700-11710.

[8] Hung C. Bai H, Karthik M. Ordered mesoporous silica particles and Si-MCM-41 for the adsorption of acetone: A comparative study. Sep. Purif. Technol 2009; 64:265-272.

[9] Liotta LF. Catalytic oxidation of volatile organic compounds on supported noble metals. Appl. Catal., B 2010; 100:403-412.

[10] Ouzzine M, Lillo-Ródenas MA, Linares-Solano A. Photocatalytic oxidation of propene in gas phase at low concentration by optimized $\mathrm{TiO}_{2}$ nanoparticles. Appl. Catal. B 2013; 134:333-343.

[11] Yang L, Jing L, Lu B, Jiang A, Wan C. Study on the removal of indoor VOCs using biotechnology. J. Hazard. Mater. 2010; 182:204-209.

[12] Kim D, Cai Z, Sorial GA, Shin H, Knnaebel K. Integrated treatment scheme of a biofilter proceded by a two-bed cyclic adsorption unit treating dynamic toluene loading. Chemical Engineering Journal 2007; 130:45-52.

[13] Fletcher AJ, Yüzak Y, Thomas KM. Adsorption and desorption kinetics for hydrophilic and hydrophobic vapors on activated carbon. Carbon 2006; 44:989-1004.

[14] Manjare SD, Ghoshal AK. Studies on adsorption of ethyl acetate vapor on activated carbon. Ind. Eng. Chem. Res 2006; 45:6563-6569. 
[15] Lillo-Ródenas MA, Carratalá-Abril J, Cazorla-Amorós D, Linares-Solano A. Usefulness of chemically activated anthracite for the abatement of VOC at low concentrations. Fuel Process Technol 2002; 77:331-336.

[16] Romero-Anaya AJ, Lillo-Ródenas MA, Linares-Solano A. Spherical activated carbons for low concentration toluene adsorption. Carbon 2010; 48:2625-2633.

[17] Romero-Anaya AJ, Lillo-Ródenas MA, Linares-Solano A. Activation of a spherical carbon for toluene adsorption at low concentration. Carbon 2014; 77:616-626.

[18] Yun JH, Hwang KY, Choi DK. Adsorption of benzene and toluene vapors on activated carbon fibers at 298, 323, and 348 K. J. Chem. Eng. Data 1998; 43:843-845.

[19] Yanxu L, Jiangyao Ch, Yinghuang S. Adsorption of multicomponent volatile organic compounds on semi-coke. Carbon; 46:858-863.

[20] Stähelin PM, Valéiro A, Guelli Ulson de Souza SMA, Da Silva A, Borges-Valle JA, Ulson De Sousa A. Benzene and toluene removal from synthetic automotive gasoline by mono and bicomponent adsorption process. Fuel 2018; 231:45-52.

[21] Guideline Series, Control of Volatile Organic Compound Emissions from Reactor Processes and Distillation Operations Processes in the Synthetic Organic Chemical Manufacturing Industry; United States Environmental Protection Agency: Research Triangle Park, North Caroline, 1993.

[22] McGinness MA. Novel new approach to VOC and HAP emission control. In Proceedings from the Twenty-second National Industrial Energy Technology Conference, Houston, TX, 2000.

[23] Lu Q, Sorial GA. Adsorption of phenolics on activated carbon-impact of pore size and molecular oxygen. Chemosphere 2004; 55:671-679.

[24] Wang K, King B, Do DD. Rate and equilibrium studies of benzene and toluene removal by activated carbon. Sep. Purif. Technol 1999; 17:53-63.

[25] Popescu M, Joly JP, Carré J, Danatoiu C. Dynamical adsorption and temperatureprogrammed desorption of VOCs (toluene, butyl acetate and butanol) on activated carbons. Carbon 2003; 41:739-748.

[26] Gironia F, Piemontea V. VOCs removal from dilute vapour streams by adsorption onto activated carbon. Chem. Eng. J 2011; 172:671-677.

[27] Lu QL, Sorial GA. The role of adsorbent pore size distribution in multicomponent adsorption on activated carbon. Carbon 2004; 42:3133-3142.

[28] Carratalá-Abril J, Lillo-Ródenas MA, Linares-Solano A, Cazorla-Amorós D. Activated carbons for the removal of low-concentration gaseous toluene at the semipilot scale. Ind Eng Chem Res 2009; 48:2066-2075.

[29] Cardoso B, Mestre AS, Carvalho AP, Pires J. Activated carbon derived from cork powder waste by $\mathrm{KOH}$ activation: Preparation, characterization, and VOCs adsorption. Ind Eng Chem Res 2008; 47:5841-5846.

[30] Jo WK, Yang CH. Granular-activated carbon adsorption followed by annular-type photocatalytic system for control of indoor aromatic compounds. Sep. Purif. Technol 2009; 66:438-442.

[31] Brasquet C, Le Cloirec P. Adsorption onto activated carbon fibers: application to water and air treatments. Carbon 1997; 35:1307-1313.

[32] Crittenden B, Patton A, Jouin C, Perera S, Tennison S, Echevarria JA. Carbon monoliths: a comparison with granular materials. Adsorption 2005; 11:537-541. 
[33] Wang Q, Liang XY, Zhang R, Liu CJ, Liu XJ, Qiao WM, et al. Preparation of polystyrene-based activated carbon spheres and their adsorption of dibenzothiophene. New Carbon Mater 2009; 24:55-60.

[34] Romero-Anaya AJ, Lillo-Ródenas MA, Linares-Solano A. Factors governing the adsorption of ethanol on spherical activated carbons. Carbon 2015; 83:240-249.

[35] White RJ, Tauer K, Antonietti M, Titirici M.M. Functional hollow carbon nanospheres by latex templating. J. Am. Chem. Soc 2010; 132:17360-17363.

[36] Wang G, Zhang Z, Wang J, Li N, Hao Z. Study of the influence of pore width on the disposal of benzene employing tunable OMCS. Ind Eng Chem Res 2015; 54:10741080.

[37] Wang H, Lashaki MJ, Fayaz M, Hashisho Z, Philips JH, Anderson JE, Nichols M. Adsorption and desorption of mixtures of organic vapors on beaded activated carbon.

Environ. Sci. Technol 2012; 46:8341-8350.

[38] Feng S, Li W, Shi Q, Li Y, Chen J, Ling Y, Asiri AM, Zhao D. Synthesis of nitrogen-doped hollow carbon nanospheres for $\mathrm{CO}_{2}$ capture. Chem. Commun 2014; 50:329-331.

[39] Gryglewicz G. Grabas K, Lorenc-Grabowska E. Preparation and characterization of spherical activated carbons from oil agglomerated bituminous coals for removing organic impurities from water. Carbon 2000; 40:2403-2411.

[40] Zhu Z, Li A, Yan L, Liu F, Zhang Q. Preparation and characterization of highly mesoporous spherical activated carbons from divinylbenzene-derived polymer by $\mathrm{ZnCl}_{2}$ activation. J Colloid Interface Sci 2007; 316:628-634.

[41] ASTM Standard Test Method for Apparent Density of Activated Carbon 1989, Designation: D 2854-89.

[42] Muñoz-Guillena MJ, Linares-Solano A, Salinas-Martínez de Lecea C. Determination of calorific values of coals by differential thermal analysis. Fuel 1992; 71:579-83.

[43] Gregg SJ, Sing KSW. Adsorption, Surface Science and Porosity. Academic Press, New York 1982.

[44] Rouquerol F, Rouquerol J, Sing K. Adsorption by powders and porous solids. Principles, methodology and applications. Academic Press, 1999.

[45] Linares-Solano A. Salinas-Martínez de Lecea C, Alcañiz-Monge J, CazorlaAmorós D. Further advances in the characterization of Microporous carbons by Physical adsorption of gases. Tanso 1998; 185:316-325.

[46] Cazorla-Amorós D, Alcañiz-Monge J, Linares-Solano A. Characterization of Activated Carbon Fibers by $\mathrm{CO}_{2}$ Adsorption. Langmuir 1996; 12:2820-2824.

[47] Lozano-Castelló D, Cazorla-Amorós D, Linares-Solano A. Usefulness of $\mathrm{CO}_{2}$ adsorption at $273 \mathrm{~K}$ for the characterization of porous carbons. Carbon 2004; 42:12311236.

[48] Jagiello J, Thommes M. Comparison of DFT characterization methods based on $\mathrm{N}_{2}, \mathrm{Ar}, \mathrm{CO}_{2}$, and $\mathrm{H}_{2}$ adsorption applied to carbons with various pore size distributions. Carbon 2004; 42:1225-1229.

[49] Román-Martínez MC, Cazorla-Amorós D, Linares-Solano A, Salinas-Martínez de Lecea C. TPD and TPR characterization of carbonaceous supports and Pt/C catalysts Carbon 1993; 31:894-902. 
[50] Carter EM, Katz LE, Speitel GE, Ramirez D. Gas-phase formaldehyde adsorption isotherm studies on activated carbon: correlations of adsorption capacity to surface functional group density. Environ. Sci. Technol. 2011; 45:6498-503.

[51] Li L, Sun Z, Li H, Keener TC. Effects of activated carbon surface properties on the adsorption of volatile organic compounds, Journal of the Air \& Waste Management Association 2012:62, 1196-1202.

[52] Li G, Xiao P, Xua D, Webley P. Dual mode roll-up effect in multicomponent nonisothermal adsorption processes with multilayered bed packing. Chemical Engineering Science 2011; 66:1825-1834.

[53] Lillo-Ródenas MA, Cazorla-Amorós D, Linares-Solano A. Behaviour of activated carbons with different pore size distributions and surface oxygen groups for benzene and toluene adsorption at low concentrations. Carbon 2005; 43:1758-1767.

[54] Lillo-Ródenas MA, Fletcher AJ, Thomas KM, Cazorla-Amorós D, Linares-Solano A. Competitive adsorption of a benzene-toluene mixture on activated carbons at low concentration. Carbon 2006; 44:1455-1463. 